\title{
PERCURSOS DA TEORIA ATOR-REDE NAS PESQUISAS BRASILEIRAS EM ADMINISTRAÇÃO
}

ACTOR-NETWORK THEORY'S PATHS IN BRAZILIAN MANAGEMENT RESEARCH

Recebido em 29.07.2020 provado em 03.12.2020

Avaliado pelo sistema double blind review

DOI: https://doi.org/10.12712/rpca.v14i4.44341

Patricia Kinast de Camillis

patriciadecamillis@gmail.com

Bolsista CAPES/BRASIL

Programa de Pós-Graduação em Administração/UNISINOS - Porto Alegre/RS, Brasil

$\underline{0000-0002-8491-9027}$

\section{Bernardo Bignetti}

bernardobignetti@gmail.com

Programa de Pós-Graduação em Administração/PUC-RS - Porto Alegre/RS, Brasil

$\underline{0000-0003-2608-2502}$

\section{Maira Petrini}

Maira.petrini@pucrs.br

Programa de Pós-Graduação em Administração/PUC-RS - Porto Alegre/RS, Brasil

$\underline{0000-0002-3914-2589}$

\section{Resumo}

O objetivo deste artigo é compreender quais percursos podem ser explorados em termos de escolhas teórico-metodológicas com relação a Teoria Ator-Rede (TAR) e quais os desdobramentos destas escolhas no campo da pesquisa em Administração no Brasil. Para tal, analisou-se qualitativamente como a TAR foi utilizada em 24 teses provenientes de Programas de Pós-Graduação em Administração brasileiros. Ao final, apontamos a existência de dois percursos: um que se aproxima e outro que se afasta da ontologia relacional e da abordagem processual da TAR. Esses caminhos se distinguem entre "usar a TAR" ou "participar da agência da TAR".

Palavras-chave: Teoria Ator-rede. Ontologia. Epistemologia. Orientações teórico-metodológicas.

\begin{abstract}
The aim of this article is to understand which paths can be explored in terms of theoreticalmethodological choices about the Actor-Network Theory and what are the consequences of these choices considering the field of Management research in Brazil. To this goal, it was analyzed qualitatively how ANT was used in 24 dissertations from Brazilian Graduate Programs in Administration. In the end, we point out the existence of two paths: one that approaches and another that moves away from relational ontology and the processual perspective of ANT. These paths are distinguished between "using ANT" or "participating in the ANT agency".
\end{abstract}

Keywords: Actor-network Theory. Ontology. Epistemology. Theoretical-methodological orientations. 


\section{Introdução}

Um dos grandes desafios nas pesquisas acadêmicas consiste na escolha adequada da lente teórica e do método que permitam conduzir uma investigação coerente ontológica e epistemologicamente, capaz de responder nossa questão de pesquisa e que traga contribuições relevantes para o campo de estudo. Ao percorrer essa trajetória, nos deparamos com a Teoria Ator-Rede (TAR), a qual, por apresentar uma ontologia relacional, propõe que o mundo pode ser organizado de modo diferente do que é (Lee \& Hassard, 1999). Desse modo, a TAR não assume a realidade como dada, mas como resultado de práticas, relações e efeitos de diversos atores, humanos e não-humanos, que se associam em variados arranjos heterogêneos (Alcadipani \& Tureta, 2009).

A TAR é uma abordagem teórico-metodológica que busca romper com o determinismo tecnológico e incluir aspectos sociais, culturais e políticos em sua investigação da realidade (Arimatéia, Valadão, \& Andrade, 2019). Na sua essência, adota uma perspectiva de análise que não parte de definições prévias sobre os fatores sociais, econômicos ou técnicos, e, assim, apresenta aspectos metodológicos que irão possibilitar ao pesquisador explicar o mundo através das relações (Alcadipani \& Hassard, 2010; Alcadipani \& Tureta, 2009, Tureta \& Alcadipani, 2009). É importante destacar que a TAR não é uma abordagem específica e homogênea, mas uma multiplicidade de conceitos desenvolvidos ao longo do tempo, iniciada por pesquisadores como Michel Callon, Bruno Latour, John Law (Lacruz, Américo, \& Carniel, 2017). A essa multiplicidade, associa-se a complexidade e densidade aportadas pelos princípios ontológicos e epistemológicos da TAR. Tal cenário pode explicar as dificuldades que estudantes e pesquisadores interessados em trabalhar com a TAR enfrentam.

É possível trabalhar com a TAR como lente teórica, como método, ou ambos? O que deve ser considerado para guiar essa decisão? Tais questionamentos são fundamentais em definir qual a melhor forma de direcionar a pesquisa, com o objetivo de usufruir o máximo de possibilidades propiciadas pela TAR e produzir contribuições relevantes para o campo. Por um lado, a TAR pode trazer uma riqueza ímpar no olhar para organizações, destrinchando a composição do social por meio das associações de elementos heterogêneos, investigando simetricamente a agência de não-humanos e proporcionando uma lente teórica-metodológica que nos permite compreender a complexidade dos fenômenos da Administração, sobretudo em temáticas relacionadas as práticas organizacionais(Santos \& Alcadipani, 2015) e as organizações como processos (Cavalcanti \& Alcadipani, 2013; Duarte \& Alcadipani, 2016). Por outro lado, pode levar a uma série de dúvidas quanto a sua operacionalização. Embora Bruno Latour afirme que "Ela (TAR) não se aplica a coisa alguma [...] (TAR) é uma teoria, [...] sobre como conceber aos atores (actantes) espaço para se expressarem" (Latour, 2005, p. 205), algumas orientações iniciais parecem necessárias para quem almeja "aventurar-se na rede da TAR."

No cenário nacional, a maior parte dos artigos publicados, enfatiza um aspecto particular da Teoria AtorRede, como, por exemplo, o conceito do enactment (Camillis \& Antonello, 2016), de translação (Valadão \& Andrade, 2017), de controvérsias (Cerretto \& Domenico, 2016), dos elementos heterogêneos (Camillis \& Antonello, 2016; Oliveira \& Valadão, 2017) assim como a visão processual (Cavalcanti \& Alcadipani, 2013) e relacional (Amantino-de-Andrade, 2004) da TAR. Além disso, constata-se que muitos artigos debatem as possibilidades da utilização da TAR para os estudos organizacionais (Alcadipani \& Tureta, 2009; Américo \& Takahashi, 2013; Cavalcanti \& Alcadipani, 2013) salientando aspectos epistemológicos (Duque \& Valadão, 2017; Tonelli, 2015) e metodológicos (Tureta \& Alcadipani, 2009). Adicionalmente, encontram-se trabalhos que fazem um levantamento da produção científica das pesquisas que empregam a TAR em uma abordagem voltada somente para quantificação e classificação dos trabalhos selecionados (Lacruz, Américo, \& Carniel, 2017).

Entretanto, observa-se uma lacuna na compreensão de como e de que maneira as pesquisas nacionais estão se apropriando e empregando a TAR em suas investigações. Ao analisarmos a maneira como o nosso campo se apropria da TAR, identificamos que, de uma forma mais ampla, existe coerência entre a 
escolha da TAR e a proposta da pesquisa, mas também são identificadas inconsistências e lacunas. Nosso olhar para essas últimas busca o aprimoramento do rigor e da qualidade nas pesquisas em Administração que buscam a TAR para compor seus quadros teóricos e metodológicos e, desta forma, que possamos não apenas acompanhar, mas também avançar nos movimentos mais contemporâneos da TAR, propondo discussões teóricas a partir da realidade brasileira. Com isso, o objetivo deste artigo é compreender quais caminhos possíveis podem ser explorados nas escolhas sobre a TAR e quais os desdobramentos destas escolhas.

Nossa contribuição é apresentar caminhos que possam servir como um guia para o pesquisador fazer suas escolhas com mais rigor e qualidade. Para tal, analisamos pesquisas nacionais que adotaram a TAR, provenientes de Programas de Pós-Graduação em Administração das universidades brasileiras em nível de doutorado. O recorte pelo doutorado se dá pelo fato de que, dada a complexidade da TAR e sua característica de imersão no campo, os pesquisadores no doutorado têm mais tempo para desenvolver a pesquisa atribuindo aprofundamento, qualidade e rigor necessários. Além disso, o texto da tese, geralmente, fornece informações mais detalhadas com relação a apropriação e operacionalização da TAR na pesquisa quando comparados à dissertação. Optou-se por não buscar artigos acadêmicos devido a duas premissas, ambas decorrentes de uma primeira imersão nas publicações. A primeira delas, trata de que muitos artigos são ensaios teóricos ou revisões de literatura sobre a TAR, não configurando uma pesquisa aplicada. A segunda premissa está pautada na constatação de que os artigos publicados, a maioria oriundos de dissertações e teses, são reduzidos e até fragmentados, se comparados aos textos originais. Desta forma, foram lidas integralmente 24 teses.

O presente artigo é composto de uma curta história sobre as trajetórias e desvios percorridos pela TAR, evidenciando seus principais conceitos, noções e diferenças. Em seguida, descrevem-se os procedimentos metodológicos, a qual precede a seção de apresentação dos resultados. A seção de discussão do trabalho apresenta os caminhos identificados nas pesquisas analisadas e propõe reflexões sobre os percursos da TAR no Brasil. Nas considerações finais, argumenta-se que não é possível ter um guia definitivo do tipo passo-a-passo para empregar a TAR, mas é possível indicar caminhos que auxiliem o pesquisador a adotála de forma mais consistente e coerente com os pressupostos da mesma.

\section{Teoria Ator- Rede: trajetórias e desvios}

A tarefa de apresentar a Teoria Ator-rede (TAR) pode ser feita através de, no mínimo, três trajetórias. Um nos leva para dentro de um laboratório no qual Bruno Latour faz sua "etnografia das ciências", descrevendo a "produção dos fatos científicos" (Latour \& Woolgar, 1997). Outro nos deixa na Baía de St Brieuc, local de extração de vieiras, onde Michel Callon apresenta a "sociologia da translação" para descrever as relações de poder nas Ciências (1986). E temos ainda uma trajetória percorrida por John Law que olha, com o interesse das ciências sociais, para como as ciências naturais são praticadas, buscando uma descrição realista desta prática (Law \& Lodge, 1984). Todas essas trajetórias, a seu modo, discutem a produção da Ciência - o que na concepção moderna existiria de mais "puro e objetivo" realizando uma crítica capaz de discutir a produção do mundo. Essas trajetórias se entrecruzam em vários momentos e os pontos de intersecção mostram algumas noções indispensáveis para compreendermos a TAR. Porém, essas trajetórias também possuem distinções, igualmente importantes. Nos próximos parágrafos compilamos essas noções e distinções.

Começaremos pelas Associações. Na TAR, o social é um efeito de múltiplas associações: é uma "trilha de associações entre elementos heterogêneos" (Latour, 2005, p. 5) ou um resultado de redes heterogêneas (Law, 1994). Embora os atores possam ter um senso de estabilidade e singularidade, segundo a TAR este é um resultado alcançado quando diferentes materiais heterogêneos são agenciados em conjunto (Callon, 1986). Desta forma, os atores tomam a sua forma e adquirem seus atributos como consequência de suas relações/associações com os outros (Law, 1994). A noção de associação é usada para substituir a obsoleta distinção entre sujeitos e objetos (Latour, 2001). A partir disso, duas questões essenciais para a pesquisa que se apropria da TAR são formuladas: (1) que ator pode ser conectado a qual outro? e (2) que ator 
pode substituir qual outro numa dada associação? Neste olhar para as associações, quando se fala em ator, devemos pensar em fluxo e movimento, em uma entidade que deixa traços. Por isso, é mais adequado falar de actante, "termo tomado da semiótica para incluir não-humanos na definição (Latour, 1999, p. 346).

Importante destacar que a TAR fala em movimento de associações e de reunião dos elementos, ou seja, o social seria "o nome do tipo de associação momentânea, caracterizada pela maneira como se reúnem as novas formas" (Latour, 2005, p. 6). Desta forma, a ação é uma das propriedades das entidades associadas (Latour, 2001), sendo necessária uma composição de forças para explicar a ação. Um dos debates mais instigantes da TAR é sobre "caixa-preta". A caixa-preta pode ser um resultado, muitas vezes momentâneo, de associações, e se refere a maneira como o trabalho científico e técnico torna-se invisível decorrente de seu próprio êxito. [...] Assim, quanto mais a ciência e a tecnologia obtêm sucesso, mais opacas e obscuras se tornam (Latour, 2001).

Observa-se que as explicações anteriores remetem ao movimento, à ação. Por isso, discute-se processo como algo que não se encerra por completo, não é um ciclo que se fecha, com etapas sequenciais indispensáveis, mas um constante ordenamento e desordenamento de humanos e não-humanos. Desta forma, a noção de processo é importante para entender que nada é dado como pronto. Uma organização não é uma instância bem delimitada, estável e representável, mas um processo instável, temporário, negociado e nunca inteiramente manifestado: entidades que podem ser compreendidas como verbos (Cooper \& Law, 2015). Nesta visão processual, a estabilidade e a própria consistência são produtos da rede de relações heterogêneas que a formam (Law, 1994). Desta forma, sob a ótica da TAR, as divisões (objetivo e subjetivo, natureza e sociedade) são entendidas como efeitos ou resultados e não algo estabelecido a priori. A rede-de-atores constitui-se em ação e não nas relações e estruturas dadas na ordem das coisas (Law \& Hassard, 1999). A discussão sobre processo é mais evidente na trajetória de John Law, como apontam Cavalcanti e Alcadipani (2013): as pesquisas e os conceitos desenvolvidos por Law (em parcerias) contribuem de maneira significativa para as discussões das organizações como processo.

A TAR discute a falsa dicotomia entre natural e social, culminando em pensar as associações entre humanos e não-humanos: atores/actantes/atuantes como protagonistas que participam e fazem processos. De acordo com Latour (1994), uma série de separações arbitrárias estariam nos impedindo de compreender o mundo a nossa volta que está repleto de híbridos. Assim, "os fenômenos são ao mesmo tempo reais, como a natureza, mas também narradas como discurso e coletivos, como a sociedade" (Latour, 1994, p. 15). Um quebra-molas, por exemplo, fixo e rígido ao chão, não é feito apenas de matéria, "está repleto de engenheiros, reitores e legisladores que misturam suas vontades e perfis históricos ao do cascalho, concreto, tinta e cálculos matemáticos”(Latour, 2001, p. 218).

Vive-se no coletivo, que são associações de humanos e não-humanos, e não em sociedade. Sociedade é um artefato imposto pelo acordo modernista (que separa homem e natureza). O coletivo se forma pelo intercâmbio de propriedades humanas e não-humanas, sendo aquilo que nos coliga a todos (Latour, 2001, 2004). Porém, não se trata de estender a subjetividade às coisas ou tratar humanos como objetos, ou ainda evitar a todo custo o emprego da distinção sujeito-objeto ao discorrer sobre o entrelaçamento de humanos e não-humanos. O que a TAR propõe é um esforço para capturar os movimentos pelos quais um dado coletivo estende seu tecido social a outras entidades. Tratar de associações de humanos e nãohumanos se refere a um regime político que busca ultrapassar a distinção sujeito-objeto (Latour, 2001). E como o próprio autor destaca "O não-humano só significa alguma coisa na diferença entre o par humano-não-humano" (Latour, 2001, p. 352).

Tratar de associações, olhar o cotidiano, contar histórias, buscar inspiração etnográfica para realizar pesquisas acadêmicas nos levam a compreender mais um elemento da TAR: a descrição como parte do método. Na descrição é preciso um esforço de transferir para o texto (ou seja, traduzir) a natureza relacional do que pesquisamos (e vivemos). Aqui é importante destacar que a TAR é uma abordagem teórico-metodológica, uma vez que também propõe superar a dicotomia teoria/método: a forma como 
podemos conhecer o mundo também constitui esse mesmo mundo (Latour, 2001). Porém, é fundamental que a descrição como parte do método não seja dissociada da noção de associação e processo.

Para realizar a descrição (do momento em que as coisas acontecem), é preciso considerar a noção de simetria generalizada. Assim, conseguimos entender, por exemplo, que a credibilidade científica é uma rede (um emaranhado) de citações, reconhecimento, dinheiro, equipamentos, dados, argumentos, artigos, leitura, pesquisadores, etc. (Latour \& Woolgar, 1997). Além disso, a unidade de análise é o social, porém, um social que é compreendido como coletivo. O princípio de simetria tem por base a afirmação de que "tudo" merece uma explicação. Por exemplo, nos estudos sobre a prática científica, tanto as origens do conhecimento verdadeiro quanto as do falso merecem ser explicadas. Segundo essa lógica, deve-se questionar, ainda, por que há uma distinção entre atores humanos e não humanos, já que não se pode assumir nenhuma diferença essencial contida na natureza das coisas a priori (Law, 1994). A simetria generalizada nos coloca na posição de "não definir, a priori, um ponto de partida da análise" (Latour \& Woolgar, 1997, p. 206). Desta forma, a simetria nos leva ao não reducionismo, que acarreta o compromisso de partir para o campo sem conceitos prontos ou reduções a priori. Da mesma forma, é preciso acatar a reflexividade que diz respeito ao fato de que o pesquisador não pode considerar-se diferente daquilo que está sendo estudado, ou seja, ele não ocupa um lugar privilegiado na análise sendo parte da rede de atores (Law, 1994).

As noções apresentadas até aqui servem para nos guiar para e através da translação, (a TAR também é conhecida como sociologia da translação) e das controvérsias (compreendida por muitos pesquisadores como sendo o método da TAR). A "translação" é um termo que se refere a todos os deslocamentos por entre atores cuja mediação é indispensável à ocorrência de qualquer ação. Em lugar de uma rígida oposição entre contexto (externo) e conteúdo (interno), as cadeias de translação referem-se ao trabalho graças ao qual os atores "modificam, deslocam e transladam seus vários e contraditórios interesses" (Latour, 2001, p. 351). "Transladar interesses significa, ao mesmo tempo, oferecer novas interpretações desses interesses e canalizar as pessoas para direções diferentes [...] os resultados de tais translações são um movimento lento de um lugar para outro" (Latour, 2005, p. 194). Para Callon (1986) os processos de translação são os momentos por meio dos quais a identidade dos atores, a possibilidade de interação e as margens de manobra são negociadas e delimitadas, assim, existe transformação. De acordo com o autor é possível compreender a translação através desses momentos, entretanto, os processos não são lineares e estão em fluxo. "Apenas são momentaneamente identificados pelo pesquisador" (Callon, 1986, p. 6). Assim, translação não se refere a fases, já que é um conceito oriundo de Michel Serres (1996, apud Tonelli, 2015) para quem o tempo é o espaço da simultaneidade.

Através de exemplos relacionados à prática científica, Latour (2000) destrincha a noção de controvérsias, descrevendo como a suspensão da controvérsia pode ser uma das razões que leva a aceitar a realidade como fato. Assim, a análise das controvérsias estaria ligada diretamente à adoção da TAR, apresentando, então, sete regras metodológicas a serem seguidas: 1) objetivar o fato em ação, enquanto ainda é objeto de controvérsias; 2) objetividade ou subjetividade é um efeito dos processos de circulação das redes; 3) ao resolvermos controvérsias, estabilizamos a Natureza; 4) ao resolvermos controvérsias, estabilizamos a Sociedade; 5) considerar o princípio de simetria para estudar os que realmente trabalham; 6) Precisamos atentar para a extensão da rede que é construída em toda situação de controvérsias; e 7) rastrear a rede que sustenta qualquer qualidade especial (para escapar da interpretação). As controvérsias são assim as várias possibilidades em construção e disputa (Latour, 2000).

Diversas críticas foram feitas à TAR. Walsham (1997) as resume em quatro principais: (i) análise limitada das estruturas sociais; (ii) postura amoral ao negligenciar questões de cunho político e moral; (iii) falha ao considerar a distinção analítica entre humanos e não humanos; e (iv) possíveis problemas a respeito de como seguir as entidades numa análise das redes. Por sua vez, Reed (1997) considera que a TAR possuiria uma neutralidade crítica. Whittle e Spicer (2008) apontam uma suposta neutralidade política. Além disso, 
estes últimos autores apontam que a visão de rede presente na TAR seria determinística, ou seja, uma visão que reificaria as relações sociais.

Respostas às críticas vieram com a Teoria Ator Rede e Depois (ANT and After), no qual alguns desvios apareceram no sentido de destacar a noção de processo da TAR. Como resposta, Latour (1999) provocou "...there are four things that do not work with actor-network theory; the word actor, the word network, the word theory and the hyphen!" (Latour, 1999, p. 15). Porém, foi John Law, juntamente com pesquisadoras como Annemarie Mol e Vick Singleton, e outros, os responsáveis pelo o esforço teórico para ampliar e aprofundar a discussão da noção de processo na TAR, o que torna a sua trajetória significativamente distinta. De acordo com Law $(1994,2002)$ o objeto deve ser entendido como contingente de toda uma complexidade que necessita ser abarcada pela análise do pesquisador. Os objetos empíricos não podem ser tomados como um fim em si mesmos, mas como manifestações de arranjos mais ou menos estáveis de uma rede de relações que veio a possibilitar sua existência ou produzi-los. Law e Singleton (2005) destacam o trabalho essencial de enfatizar não apenas como os objetos se tornam estáveis, mas também os arranjos que os modificam, destacando a rede de infindáveis relações nunca inteiramente representáveis. Os objetos, segundo a TAR, seriam híbridos que não cessariam de misturar humanos e não-humanos (Law, 1994). A partir disso, outras discussões e noções se tornariam relevantes para a TAR e Depois. O destaque para a noção de processo veio também com o conceito de enactment. Embora a proposta do termo enactment não busque enfrentar diretamente todas as críticas, contribui para que a TAR não tenha uma visão neutra nem mecânica em suas análises e descrições, além de poder contribuir com a visão de organização como resultado e produto de processos contínuos ao realizarmos nossas pesquisas em Administração (Camillis \& Antonello, 2016).

Vale destacar que a noção de processo, trazida por John Law, vinha sendo tratada muito antes das críticas à TAR. O autor já discutia ordering, organiżing desde 1988, quando deu início a uma pesquisa buscando compreender a organização, a gestão e o sucesso de mercado da ciência. Para Law (1994) o próprio sistema de translação envolvido no processo de organizar, não oferece garantias de fidedignidade ao acontecimento. As coisas percebidas em campo, na visão do autor, não passariam de efeitos relacionais mutantes, produtos de redes dinâmicas e, não, de estruturas sincrônicas. Se algo, então, se estabiliza por um momento, a ponto de ser visto ou notado (ou cheirado, sentido, etc.), deve-se a uma estabilidade pragmática temporária (Law, 1994). Além disso, Law e Mol (1995) propuseram que a TAR seria melhor compreendida como uma semiótica material.

A noção de objeto mutável foi desenvolvida por Mol e Law (1994), em outro estudo empírico no qual analisaram a anemia na Holanda e na África concomitantemente: um exemplo de como um mesmo objeto é mutável em contingências locais específicas, justamente devido às redes heterogêneas que o constituem. Observa-se que considerar objetos como uma organização mutável ou fluida implica dizer que sobre eles não existe um ponto de vista privilegiado, já que nunca se mostram bem definidos ou com contornos nítidos. É por meio de sua fluidez e plasticidade que a organização melhor exerce poder e adquire robustez (Cavalcanti \& Alcadipani, 2013). Law e Singleton (2005) afirmam que pesquisar esse tipo de objeto é algo factível, mas exige um tipo de radicalismo ontológico e metodológico. Tal radicalismo reforça a necessidade, apresentada por John Law, de tratar a complexidade na prática.

A necessidade de compreender os modos de organizar empiricamente foi pontuada por Law e Urry (2004). Os autores afirmam que, mesmo se estamos tratando de uma postura empirista de produzir conhecimento a respeito da complexidade, uma abordagem metodológica não representa ou acessa uma realidade previamente constituída, mas uma metodologia participa e é expressão de uma realidade própria à postura metodológica adotada. Ao analisar redes heterogêneas por meio da TAR, Law (1992) destaca que a preocupação central reside em como estes arranjos formados por pequenas partes conseguem mantê-las unidas e coesas, mas também se modificam. Além disso, Law (1994) frisa o caráter material da noção de modo de organizar como manifestações da rede heterogênea de relações humanas e não humanas que constituem uma organização. Esse aspecto processual é fortemente destacado e debatido 
na TAR e Depois, fazendo um esforço para dar conta de complexidades relegadas a compreender os "comos", os processos. De acordo com Law (2004) métodos não apenas descrevem a realidade, mas ajudam a criá-la. Considerando um mundo complexo e bagunçado, no qual realidades são provisoriamente estáveis, o método está imbricado nisso e precisaremos aprender a pensar, a praticar, a saber, a relacionar em novas formas. O autor discute o método "assemblage" que é uma combinação entre detectar a realidade e amplificar a realidade (Law, 2004, p. 14).

Hoje, 20 anos após o livro Actor Network Theory and After, o qual, de acordo com Block, Farías e Robert (2020) teria marcado o fim da TAR como uma posição teórica imbricada no campo da Science and Technology Studies (STS), iniciando um amplo e aberto espaço para pesquisas em outros campos, a partir do desenvolvimento de conceitos como fractalidade (Law, 2002), multiplicidade (Mol, 2002) e performatividade (Mackenzie, Muniesa, \& Siu, 2007). Esse arcabouço teórico acrescido à TAR e Depois foi denominado de "Post-ANT" por Gad e Jensen (2010). Embora a TAR tenha se tornado conhecida em função de um repertório conceitual preocupado com a simetria generalizada, com redes e com nãohumanos, nos últimos anos, muitas pesquisas têm se tornado algo além de TAR e Depois ou Pós-TAR adotando o que os autores chamam de experimentar com a TAR e a partir da TAR os seus aspectos mutáveis. Esse movimento, denominado de "Near ANT" tem levado à ampliação e aprofundamento dos debates, de maneira mais livre, e apresentado novos arcabouços conceituais (Blok, Farías, \& Roberts., 2020). Vale destacar que esse movimento foi identificado pelos referidos autores em pesquisas fora do Brasil.

Resumidamente, Near $A N T$ são modos de pensar e falar próximos à TAR, que não apenas desenrolam os conceitos, as estratégias de pesquisa e as experiências de escrita da TAR, mas as mantêm por perto, como fontes de questionamento, problematização e inspiração. Refutando distinções que possam estabilizar, institucionalizar ou canonizar o que é a TAR, pensar próximo a TAR (Near ANT) é considerar que a TAR não está sozinha, mas é parte de um enactar de pesquisas sociais mais-que-humanas operando em um campo expandido de problematizações pós/não/mais-que-humanistas deste mundo comum que construímos e habitamos (Blok, Farías, \& Roberts, 2020).

Pensando a partir da TAR, assumimos que algo, como o nosso objeto de pesquisa, adquire sentido somente por meio das relações que ele estabelece em uma rede de significantes, levando-nos a descrever o aspecto relacional de como determinada realidade objetiva se sustenta. Soma-se a isso, e considerando que a TAR possui uma característica mutante, as pesquisas que se apropriam das suas noções podem realizar diferentes percursos. São esses caminhos que buscamos desvendar nas pesquisas em Administração analisadas aqui, para entender onde estamos e para onde podemos ir.

\section{Procedimentos metodológicos}

Para compreender como a TAR vem sendo apropriada nas pesquisas acadêmicas no campo da Administração, realizou-se uma revisão de literatura, em consonância com as recomendações de Schwarz et al. (2007), Rowe (2014) e Okoli (2015) no tangente às estratégias para uma revisão de literatura. O presente trabalho empregou, sobretudo, as sugestões desses autores nas etapas de coleta de publicações, análises descritivas, sínteses e interpretações de resultados, assim como tendo em vista às oportunidades de futuras pesquisas. Para tanto, realizou-se uma busca pelas teses nacionais por meio da base de dados da Biblioteca Digital Brasileira de Teses e Dissertações (BDTD). A escolha por essa base de dados decorreu pelo fácil acesso e pela extensa quantidade de teses e de dissertações nacionais cadastradas.

A pesquisa ao acervo da BDTD ocorreu em dois momentos distintos, em dezembro de 2018 e em agosto de 2019, resumidos no Quadro 1 e detalhados a seguir. 
Quadro 1 - Pesquisa na base de dados BDTD.

\begin{tabular}{|c|c|c|c|c|}
\hline \multicolumn{5}{|c|}{$1^{a}$ Busca de literatura (dezembro de 2018 ) } \\
\hline Local de busca & $\begin{array}{c}\text { Termo usado na } \\
\text { busca }\end{array}$ & $\begin{array}{l}\text { Resultado } \\
\text { Total }\end{array}$ & $\begin{array}{c}\text { Resultado com } \\
\text { trabalhos de } \\
\text { Departamentos de } \\
\text { Administração } \\
\end{array}$ & $\begin{array}{c}\text { Trabalhos analisados } \\
\text { que empregaram a } \\
\text { TAR }\end{array}$ \\
\hline $\begin{array}{l}\text { Biblioteca Digital } \\
\text { Brasileira de Teses } \\
\text { e Dissertações } \\
\text { (BDTD) }\end{array}$ & $\begin{array}{l}\text { "Teoria Ator- } \\
\text { Rede" ou "Teoria } \\
\text { Ator Rede" }\end{array}$ & $\begin{array}{l}262 \text { trabalhos } \\
\text { (teses e } \\
\text { dissertações) }\end{array}$ & $\begin{array}{l}33 \text { trabalhos (teses e } \\
\text { dissertações) }\end{array}$ & 20 teses \\
\hline \multicolumn{5}{|c|}{$2^{a}$ Busca de literatura (agosto de 2019) } \\
\hline Local de busca & $\begin{array}{l}\text { Termo usado na } \\
\text { busca }\end{array}$ & $\begin{array}{l}\text { Resultado } \\
\text { Adicional } \\
\text { Encontrado }\end{array}$ & $\begin{array}{l}\text { Resultado com } \\
\text { trabalhos de } \\
\text { Departamentos de } \\
\text { Administração }\end{array}$ & $\begin{array}{l}\text { Trabalhos analisador } \\
\text { que empregaram a } \\
\text { TAR }\end{array}$ \\
\hline $\begin{array}{l}\text { Biblioteca Digital } \\
\text { Brasileira de Teses } \\
\text { e Dissertações } \\
\text { (BDTD) }\end{array}$ & $\begin{array}{l}\text { "Teoria da Ator- } \\
\text { Rede" e "Teoria } \\
\text { do Ator-Rede }\end{array}$ & $\begin{array}{l}49 \text { trabalhos } \\
\text { (teses e } \\
\text { dissertações) }\end{array}$ & $\begin{array}{l}05 \text { trabalhos (teses e } \\
\text { dissertações) }\end{array}$ & 4 teses \\
\hline
\end{tabular}

Fonte: elaborado pelos autores (2020).

Primeiramente, empregou-se, o termo "Teoria Ator-Rede" ou "Teoria Ator Rede" no campo de busca da base de dados da BDTD, resultando em de 262 trabalhos de dissertações e de teses, oriundos de diversas áreas acadêmicas, como dos departamentos de Comunicação, Música, Jornalismo, Psicologia, Pedagogia e Ciências Sociais, entre outros. Deste modo, foi necessário selecionar somente os trabalhos provenientes dos departamentos de Administração, resultando em 33 pesquisas identificadas, sendo que 32 pesquisas, de fato, empregaram a TAR em suas pesquisas. Destas, 20 pesquisas eram oriundas de teses de doutorado e 12 pesquisas provenientes de dissertações.

Por considerar a TAR uma abordagem complexa, que requer um aprofundamento teórico e tempo de campo para pesquisa, optou-se em focar nas teses de doutorado para a presente análise. Ao analisar as 20 teses, observou-se uma demanda por uma nova busca, visto que alguns pesquisadores se referiam a TAR como a Teoria do Ator-Rede. Por conseguinte, num segundo momento, ampliou-se a busca por teses na mesma base, considerando, além dos termos usados na primeira busca, os termos "Teoria da Ator-Rede" e "Teoria do Ator-Rede", resultando em 49 novos resultados de teses e dissertações, em diferentes áreas acadêmica. Novamente, considerando somente os trabalhos provindos dos departamentos de administração, identificou-se 04 novas teses com a temática em questão. Em suma, 24 teses foram analisadas de modo a conhecer as diferentes aplicações da TAR empregadas nas pesquisas de administração brasileiras. O Quadro 2 destaca informações gerais sobre a temáticas das pesquisas. 
Quadro 2-Informações gerais referentes as teses examinadas.

\begin{tabular}{|c|c|c|c|c|}
\hline Autor (Ano) & Objeto de estudo & $\begin{array}{c}\text { Palavras-chaves (exceto } \\
\text { TAR) }\end{array}$ & Área de pesquisa & $\begin{array}{c}\text { Duração da } \\
\text { Pesquisa de campo }\end{array}$ \\
\hline $\begin{array}{l}\text { Christopoulous } \\
\text { (2008) }\end{array}$ & $\begin{array}{l}\text { Processo de } \\
\text { sustentação das } \\
\text { Comunidades Virtuais } \\
\text { de Aprendizagem e } \\
\text { Prática }\end{array}$ & $\begin{array}{l}\text { Comunidades de prática; } \\
\text { identidade; aprendizagem }\end{array}$ & $\begin{array}{l}\text { Sistemas de } \\
\text { Informação }\end{array}$ & $\begin{array}{l}\text { Setembro de } 2006 \text { a } \\
\text { Setembro de } 2007\end{array}$ \\
\hline Faria (2010) & $\begin{array}{l}\text { Inovação a partir da } \\
\text { adoção da Tecnologia } \\
\text { da Informação e } \\
\text { Comunicação (TIC) } \\
\text { no ramo hospitalar - } \\
\text { adoção do prontuário } \\
\text { eletrônico do paciente } \\
\text { (PEP) }\end{array}$ & $\begin{array}{l}\text { Prontuário eletrônico do } \\
\text { paciente; rede tecno- } \\
\text { econômica; inovação; gestão } \\
\text { hospitalar }\end{array}$ & $\begin{array}{l}\text { Não consta no } \\
\text { documento da } \\
\text { tese }\end{array}$ & $\begin{array}{l}\text { Abril de } 2009 \text { a maio } \\
\text { de } 2010 .\end{array}$ \\
\hline Teles (2010) & $\begin{array}{l}\text { Evolução do } \\
\text { programa Piraí Digital } \\
\text { (inclusão digital). }\end{array}$ & $\begin{array}{l}\text { Pirai digital; inclusão digital; } \\
\text { tecnologia da informação; } \\
\text { Brasil }\end{array}$ & $\begin{array}{l}\text { Não consta no } \\
\text { documento da } \\
\text { tese }\end{array}$ & $\begin{array}{l}\text { Agosto de } 2007 \text { a } \\
\text { outubro } 2009\end{array}$ \\
\hline Adachi (2011) & $\begin{array}{l}\text { Governança da } \\
\text { Internet nacional por } \\
\text { meio da história da } \\
\text { CGI.br }\end{array}$ & $\begin{array}{l}\text { Comitê gestor da internet no } \\
\text { Brasil; gestão da informação; } \\
\text { sociedade da informação; } \\
\text { políticas públicas }\end{array}$ & $\begin{array}{l}\text { Não consta no } \\
\text { documento da } \\
\text { tese }\end{array}$ & $\begin{array}{l}\text { Julho de } 2008 \text { a } \\
\text { janeiro de } 2010\end{array}$ \\
\hline Santos (2011) & $\begin{array}{l}\text { Trabalho móvel em } \\
\text { aeroportos e aviões }\end{array}$ & $\begin{array}{l}\text { Trabalho móvel; espaço de } \\
\text { trabalho; tecnologias de } \\
\text { informação e comunicação; } \\
\text { aeroportos e aviões }\end{array}$ & $\begin{array}{l}\text { Estudos } \\
\text { Organizacionais }\end{array}$ & Março a julho de 2010 \\
\hline Tureta (2011) & $\begin{array}{l}\text { Práticas organizativas } \\
\text { da produção do desfile } \\
\text { de uma escola de } \\
\text { samba }\end{array}$ & $\begin{array}{l}\text { Práticas organizativas; escolas } \\
\text { de samba; etnografia; carnaval }\end{array}$ & $\begin{array}{l}\text { Estudos } \\
\text { Organizacionais }\end{array}$ & $\begin{array}{l}\text { Novembro } 2008 \text { a } \\
\text { outubro } 2010\end{array}$ \\
\hline $\begin{array}{l}\text { Andrade } \\
(2013)\end{array}$ & $\begin{array}{l}\text { Contribuição do } \\
\text { sistema Projudi para o } \\
\text { processo de } \\
\text { informatização do } \\
\text { Poder Judiciário } \\
\text { brasileiro }\end{array}$ & $\begin{array}{l}\text { Direito e informática; sistemas } \\
\text { de recuperação da informação; } \\
\text { poder judiciário; automação }\end{array}$ & $\begin{array}{l}\text { Gestão e } \\
\text { Organizações }\end{array}$ & $\begin{array}{l}\text { Setembro de } 2010 \text { a } \\
\text { maio de } 2013\end{array}$ \\
\hline Pinto (2013) & $\begin{array}{l}\text { Implementação de um } \\
\text { Centro de Serviços } \\
\text { Compartilhados (CSC) }\end{array}$ & $\begin{array}{l}\text { Organiə̌ing; cartografia de } \\
\text { controvérsias; centro de } \\
\text { serviços compartilhados }\end{array}$ & $\begin{array}{l}\text { Não consta no } \\
\text { documento da } \\
\text { tese }\end{array}$ & $\begin{array}{l}\text { Abril } 2011 \text { a Julho } \\
2012\end{array}$ \\
\hline $\begin{array}{l}\text { Cavalheiro } \\
\text { (2014) }\end{array}$ & $\begin{array}{l}\text { Cooperação entre } \\
\text { agências de patentes } \\
\text { de TI }\end{array}$ & $\begin{array}{l}\text { Sistemas de informação } \\
\text { gerencial; internet na } \\
\text { administração pública; } \\
\text { propriedade intelectual; } \\
\text { transferência de tecnologia }\end{array}$ & $\begin{array}{l}\text { Não consta no } \\
\text { documento da } \\
\text { tese }\end{array}$ & $\begin{array}{l}\text { Setembro de } 2011 \text { a } \\
\text { maio de } 2013\end{array}$ \\
\hline
\end{tabular}




\begin{tabular}{|c|c|c|c|c|}
\hline Autor (Ano) & Objeto de estudo & $\begin{array}{c}\text { Palavras-chaves (exceto } \\
\text { TAR) }\end{array}$ & Área de pesquisa & $\begin{array}{c}\text { Duração da } \\
\text { Pesquisa de campo }\end{array}$ \\
\hline $\begin{array}{l}\text { Fornazin } \\
(2015)\end{array}$ & $\begin{array}{l}\text { Implantação de um } \\
\text { Sistema de } \\
\text { Informação em Saúde } \\
\text { em um hospital } \\
\text { público }\end{array}$ & $\begin{array}{l}\text { Saúde; inovações tecnológicas; } \\
\text { sistemas de recuperação da } \\
\text { informação; administração } \\
\text { pública }\end{array}$ & $\begin{array}{l}\text { Não consta no } \\
\text { documento da } \\
\text { tese }\end{array}$ & $\begin{array}{l}\text { Outubro } 2010 \text { a } \\
\text { janeiro de } 2012\end{array}$ \\
\hline Duarte (2015) & $\begin{array}{l}\text { Organização } \\
\text { (organiz̨ing) de um } \\
\text { teatro musical } \\
\text { (indústria criativa) }\end{array}$ & $\begin{array}{l}\text { Organizar; indústrias criativas; } \\
\text { teatro musical; etnografia }\end{array}$ & $\begin{array}{l}\text { Estudos } \\
\text { Organizacionais }\end{array}$ & $\begin{array}{l}\text { De maio } 2013 \text { a abril } \\
2014\end{array}$ \\
\hline Pereira (2016) & $\begin{array}{l}\text { Acesso e a distribuição } \\
\text { de água para } \\
\text { populações rurais } \\
\text { difusas do semiárido } \\
\text { por meio de políticas } \\
\text { públicas }\end{array}$ & $\begin{array}{l}\text { Água; convivência com o } \\
\text { semiárido; combate à seca; ação } \\
\text { pública }\end{array}$ & $\begin{array}{l}\text { Governo e } \\
\text { Sociedade Civil } \\
\text { em Contexto } \\
\text { Subnacional }\end{array}$ & $\begin{array}{l}\text { Agosto de } 2015 \text { a } \\
\text { setembro de } 2016\end{array}$ \\
\hline Soares (2016) & $\begin{array}{l}\text { Inclusão Digital e } \\
\text { Participação } \\
\text { Eletrônica }\end{array}$ & $\begin{array}{l}\text { Comunicação; inovações } \\
\text { tecnológicas; tecnologia da } \\
\text { informação; redes locais sem } \\
\text { fio; redes locais de computação; } \\
\text { redes sociais; inclusão digital }\end{array}$ & $\begin{array}{l}\text { Não consta no } \\
\text { documento da } \\
\text { tese }\end{array}$ & $\begin{array}{l}\text { De abril a maio de } \\
2016\end{array}$ \\
\hline Luz (2016) & $\begin{array}{l}\text { Adoção de estratégia } \\
\text { emergente na lógica da } \\
\text { multidão }\end{array}$ & $\begin{array}{l}\text { Estratégia emergente; estratégia } \\
\text { como prática; multidão; comum }\end{array}$ & $\begin{array}{l}\text { Não consta no } \\
\text { documento da } \\
\text { tese }\end{array}$ & $\begin{array}{l}\text { Junho de } 2015 \text { a } \\
\text { agosto de } 2015\end{array}$ \\
\hline Camillis (2016) & $\begin{array}{l}\text { Organizar (organizing) } \\
\text { na bioconstrução }\end{array}$ & $\begin{array}{l}\text { Bioconstrução; cooperação; } \\
\text { enact, práticas }\end{array}$ & $\begin{array}{l}\text { Não consta no } \\
\text { documento da } \\
\text { tese }\end{array}$ & $\begin{array}{l}\text { Janeiro de } 2014 \text { a } \\
\text { fevereiro de } 2016\end{array}$ \\
\hline $\begin{array}{l}\text { Lemos Júnior } \\
\text { (2017) }\end{array}$ & $\begin{array}{l}\text { Configuração de valor } \\
\text { em um Modelo de } \\
\text { Negócio }\end{array}$ & $\begin{array}{l}\text { Modelo de negócio; } \\
\text { configuração de valor; arranjo } \\
\text { organizacional; pós- } \\
\text { estruturalismo. }\end{array}$ & $\begin{array}{l}\text { Não consta no } \\
\text { documento da } \\
\text { tese }\end{array}$ & $\begin{array}{l}\text { Fevereiro } 2017 \\
\text { (entrevistas) }\end{array}$ \\
\hline Sela (2017) & $\begin{array}{l}\text { Atuação de atores na } \\
\text { formação de políticas } \\
\text { públicas }\end{array}$ & $\begin{array}{l}\text { Formação de agenda; inclusão } \\
\text { financeira; atores; agenda de } \\
\text { inclusão financeira }\end{array}$ & $\begin{array}{l}\text { Administração } \\
\text { Pública e } \\
\text { Governo }\end{array}$ & $\begin{array}{l}\text { Outubro a dezembro } \\
2016 \text { (entrevistas) }\end{array}$ \\
\hline $\begin{array}{l}\text { Cavalheiro } \\
(2017)\end{array}$ & $\begin{array}{l}\text { Transformação de } \\
\text { uma cidade num } \\
\text { Destino Turístico } \\
\text { Inteligentes (Smart } \\
\text { Tourism Destination) }\end{array}$ & $\begin{array}{l}\text { Viagens e Turismo; cidades } \\
\text { inteligentes; destino turístico } \\
\text { inteligente; tecnologia de } \\
\text { informação e comunicação; } \\
\text { valor público. }\end{array}$ & $\begin{array}{l}\text { Não consta no } \\
\text { documento da } \\
\text { tese }\end{array}$ & Não identificado \\
\hline Alverga (2017) & $\begin{array}{l}\text { Implementação de um } \\
\text { Sistema de } \\
\text { Informação }\end{array}$ & $\begin{array}{l}\text { Implementação de Sistemas de } \\
\text { Informação; controvérsias; } \\
\text { translação. }\end{array}$ & $\begin{array}{l}\text { Não consta no } \\
\text { documento da } \\
\text { tese }\end{array}$ & Entrevistas: 01 mês \\
\hline Bussular (2017) & $\begin{array}{l}\text { Aprendizagem nos } \\
\text { processos } \\
\text { organizativos de } \\
\text { desastres }\end{array}$ & $\begin{array}{l}\text { Desastres; crime-desastre da } \\
\text { Samarco/Vale/BHP; } \\
\text { aprendizagem organizativa }\end{array}$ & $\begin{array}{l}\text { Não consta no } \\
\text { documento da } \\
\text { tese }\end{array}$ & $\begin{array}{l}\text { Setembro de } 2013 \text { a } \\
\text { Setembro de } 2016\end{array}$ \\
\hline
\end{tabular}




\begin{tabular}{|c|c|c|c|c|}
\hline Autor (Ano) & Objeto de estudo & $\begin{array}{c}\text { Palavras-chaves (exceto } \\
\text { TAR) }\end{array}$ & Área de pesquisa & $\begin{array}{c}\text { Duração da } \\
\text { Pesquisa de campo }\end{array}$ \\
\hline Valadão (2014) & $\begin{array}{l}\text { Bases sociotécnicas } \\
\text { transladadas em } \\
\text { rotinas }\end{array}$ & $\begin{array}{l}\text { Tecnologia social; pedagogia da } \\
\text { alternância; rotinas; mudanças }\end{array}$ & $\begin{array}{l}\text { Não consta no } \\
\text { documento da } \\
\text { tese }\end{array}$ & $\begin{array}{l}\text { Novembro de } 2012 \text { a } \\
\text { junho de } 2013\end{array}$ \\
\hline Ramos (2009) & $\begin{array}{l}\text { Evolução da Política } \\
\text { Nacional de } \\
\text { Informática }\end{array}$ & $\begin{array}{l}\text { Não consta no documento da } \\
\text { tese }\end{array}$ & $\begin{array}{l}\text { Não consta no } \\
\text { documento da } \\
\text { tese }\end{array}$ & $\begin{array}{l}\text { Fevereiro de } 2009 \text { a } \\
\text { Julho de } 2009\end{array}$ \\
\hline Canepa (2010) & $\begin{array}{l}\text { Processo de } \\
\text { Implementação de } \\
\text { Sistema de Gestão } \\
\text { Empresarial }\end{array}$ & $\begin{array}{l}\text { Sistema de gestão empresarial; } \\
\text { processo de implementação; } \\
\text { infraestrutura de TI; drifting }\end{array}$ & $\begin{array}{l}\text { Não consta no } \\
\text { documento da } \\
\text { tese }\end{array}$ & $\begin{array}{l}\text { Junho de } 2008 \text { a julho } \\
2009\end{array}$ \\
\hline Burtet (2019) & $\begin{array}{l}\text { Inovação social no } \\
\text { movimento maker no } \\
\text { Brasil }\end{array}$ & $\begin{array}{l}\text { Inovação; inovação inclusiva; } \\
\text { movimento maker }\end{array}$ & $\begin{array}{l}\text { Não consta no } \\
\text { documento da } \\
\text { tese }\end{array}$ & $\begin{array}{l}\text { Julho de } 2016 \text { a julho } \\
2018\end{array}$ \\
\hline
\end{tabular}

Fonte: elaborado pelos autores (2020).

De modo a analisar qualitativamente os trabalhos identificados, foi necessário ler e examinar a totalidade dessas pesquisas. Essa leitura foi realizada duas vezes, em dois momentos distintos, de modo a melhor examinar os trabalhos investigados. Consequentemente, alguns critérios foram necessários para organizar e sintetizar a extensa gama de informações provindas desses trabalhos. Assim, foram usados como critérios para elementos de análise: a unidade de análise, o modo como a TAR foi usada na pesquisa (como lente teórica, método ou ambos), a estratégia de pesquisa, isto é, a metodologia informada, as técnicas de coleta de dados utilizadas, a técnica para análise de dados; além disso, consideramos, a duração da pesquisa em campo, os principais conceitos abordados da TAR e seus respectivos autores e o uso de outras teorias para compor o quadro explicativo da tese.

Na primeira leitura dos trabalhos, foi possível perceber três formas gerais de abordar a unidade de análise investigadas nas teses nacionais: i) como fenômeno (F), ii) como processo (P) e iii) como prática (PA). No segundo momento de reler os trabalhos e após extenso debate entre os autores desse artigo, percebeuse uma subdivisão, sendo necessária uma distinção entre processo como procedimento, etapa, e ação (Pp), e processo como organiz̨ing, enactment, processo recursivo usado no gerúndio (Po). Da mesma forma, identificamos uma diferença no que se refere às práticas: práticas como uma ação em si, um modo de executar algo (PAa); e práticas, onde o "fazer" e "pensar" são indissociáveis (PAt). A abordagem de unidade de análise que denominamos fenômeno (F) está relacionado com um acontecimento, evento, marco histórico investigado. No Quadro 3 apresenta-se um resumo conceitual da subdivisão elaborada. 
Quadro 3-Maneiras de abordar a unidade de análise identificadas nas teses nacionais.

\begin{tabular}{|l|l|l|}
\hline Nome & Definição \\
\hline Fenômeno (F) & Processo (Pp) & $\begin{array}{l}\text { Maneira de efetuar uma ação, etapa ou procedimento; maneira } \\
\text { ordenada de fazer algo; ordem. }\end{array}$ \\
\hline Processo & Processo (Po) & $\begin{array}{l}\text { Processo via organižng, enactment ou processo recursivo } \\
\text { (gerúndio). }\end{array}$ \\
\hline Prática & Prática (PAa) & $\begin{array}{l}\text { Trata das ações em si; refere-se a maneira de exercer um } \\
\text { conhecimento; aplicação das regras e dos princípios de um } \\
\text { procedimento. }\end{array}$ \\
\cline { 2 - 3 } & Prática (PAt) & $\begin{array}{l}\text { Emprega princípios das Teorias Baseadas em Prática (TBP), } \\
\text { investigando os fazeres e dizeres, que são indissociáveis e que } \\
\text { constituem uma organização. }\end{array}$ \\
\hline
\end{tabular}

Fonte: Elaborado pelos autores (2020)

Outra diferença de abordagem, identificado na segunda etapa de leitura das teses, diz respeito a temporalidade da unidade de análise da pesquisa, identificando-se pesquisas realizadas a respeito do passado, do presente, ou ambos. Essa constatação emergiu do próprio campo, isto é, do texto das pesquisas analisadas, sem uma definição prévia.

Nem todas as pesquisas que apropriaram a Teoria Ator-Rede em sua investigação declaram explicitamente o modo como empregaram essa teoria: se apropriaram a TAR como lente teórica, como método ou ambos. Para estipular um critério para essa distinção, foi adotada a maneira como o próprio pesquisador relatou essa articulação na pesquisa, ou seja, se mencionou somente na seção teórica do trabalho, somente na seção metodológica ou em ambas as seções. A seguir, apresentaremos os resultados encontrados para em seguida fazer a discussão dos achados.

\section{Apresentação dos resultados}

Ao iniciarmos essa seção, cabe destacar que nossos resultados são apresentados buscando uma exploração qualitativa, que permita abrir possibilidades para pensarmos em como trabalhar com a TAR de maneira coerente, mas também crítica e reflexiva. Importante relembrar que nosso objetivo é identificar os percursos e pensar caminhos futuros, por isso, pensando alegoricamente, a quantidade de paralelepípedos do trajeto não será contada, entretanto vamos observar a paisagem, suas nuances e mudanças. Além disso, consideramos que todas as pesquisas aqui analisadas foram apresentadas e julgadas por bancas avaliadoras e, sendo assim, merecedoras do título de tese.

Iniciamos pelo item unidade de análise. Conforme mencionado, pode-se discernir cinco principais maneiras de abordar a unidade de análise nas pesquisas investigadas, que estão relacionadas: a um fenômeno $(\mathrm{F})$, aos processos (Pp e $\mathrm{Po}$ ) e às práticas (PAa e PAt) no campo da Administração. Por fenômeno (F), entende-se um acontecimento passível de observação. Como exemplo, enquadram-se as pesquisas relacionadas ao Desenvolvimento da Governança da Internet (Adachi, 2011), ao Trabalho Móvel (H. Santos, 2011), à Estratégia Emergente na Lógica da Multidão (Luz, 2016) e o Arranjo Organizacional (Lemos Júnior, 2017).

Já o nível de processo $(\mathrm{Pp})$ diz respeito ao modo de efetuar uma ação, etapa ou procedimento, como por exemplo, na investigação da contribuição do sistema Projudi para o processo de informatização do Poder Judiciário brasileiro (Andrade, 2013), da inclusão digital e participação eletrônica (Soares, 2016), da implantação de um Sistema de Informação (Alverga, 2017). Por sua vez, processo (Po) trata de um processo numa visão relacional, em convergência com os conceitos de organižing e enactment, que se aproximam da epistemologia do processo proposta por Cooper (1976). Exemplo de pesquisa usando esta ênfase pode ser visualizada no estudo do processo produção de um espetáculo de teatro musical Duarte (2016). 
De modo adicional, o nível de práticas (PAa) é alusivo às ações em si, relativo à prática existente e que compõe as organizações, como no estudo da Implantação de um Sistema de Informação em Saúde em um hospital público (Fornazin, 2015). Por fim, observa-se uma abordagem de práticas (PAt) contemplando as Teorias (ou Estudos) Baseadas em Práticas, investigando os fazeres e dizeres que compõe uma organização, como ilustra, entre outras, as pesquisas de Tureta (2011), de Camillis (2016), Pereira (2016) e Bussular (2017). Com relação à temporalidade referente à unidade de análise, poucas teses abordaram, de maneira prioritária, apenas o tempo presente, acompanhando os actantes, tecendo as redes e descrevendo a realidade enquanto performada/enactada. As que fizeram isso, não abriram mão de utilizar a técnica de observação participante e anotações em diário de campo para coleta de dados, entre outras técnicas, como fez, por exemplo, Bussular (2017). As pesquisas que trataram de algo passado, valeram-se de entrevistas e análise de documentos, como fez, por exemplo Teles (2010).

Em relação ao modo como a TAR foi empregada, na grande maioria das pesquisas (17 trabalhos), os pesquisadores declaram adotá-la como lente teórica e método, ao mesmo tempo. Entretanto, o Estudo de Caso, como método e/ou estratégia de pesquisa, foi literalmente referenciado em 15 trabalhos, sendo a coleta de dados realizada sobretudo por meio entrevistas e análise de documentos, apontando uma certa contradição com a afirmação de que a TAR estaria sendo utilizada como método. Nesses casos, a maioria declarou tratar-se de Estudos de Caso Interpretativistas e/ou Construtivistas. Alguns indicaram ter utilizado o método de "seguir os atores" e descreviam a técnica de entrevistas da "bola de neve" para coleta de dados. Poucos afirmam abordar o método da TAR através de estratégias que exigiam trabalho de campo prolongado, como a praxiografia (Duarte, 2015; Pereira, 2016), assemblage (Camillis, 2016), cartografia das controvérsias (Bussular, 2017), binterland (Burtet, 2019) e etnografia (Tureta, 2011).

Sobre o uso da TAR como lente teórica, alguns trabalhos fizeram articulações com outras bases conceituais, como por exemplo a Teoria da Estruturação de Giddens (1984), em Adachi (2011), o Organizing de Weick (1979), em Pinto (2013), Organizing de Cooper \& Burrel (1988), em Duarte (2015) e as Práticas de Schtazki, em Camillis (2016) e Knowing de Gherardi (Estudos Baseados em Prática) em Bussular (2017). Os trabalhos que se apropriaram da TAR declaradamente apenas como lente teórica aplicaram conceitos da Teoria Ator-Rede, como o processo de translação/ tradução - dividido e analisado em fases - e as controvérsias - como a identificação de perspectivas opostas - para tratar de um estudo de caso em particular. Observa-se que esses trabalhos não refletiam as discussões da TAR e Depois em suas abordagens. Por fim, destaca-se que apenas como método, a TAR não foi empregada nas teses analisadas.

No que tange às técnicas de coleta de dados, a maioria dos autores usaram entrevistas, análise de documentos, observação não-participante e, em alguns casos, observação participante, com uso de diários de campo, entrevistas semiestruturadas e até mesmo entrevistas (ou conversas) informais, como Valadão (2014), Camillis (2016), Bussular (2017) e Burtet (2019). As teses nas quais os pesquisadores afirmaram ter utilizado a técnica de observação participante para coletar dados, a permanência em campo foi, em geral, superior a 06 meses. Por outro lado, as pesquisas que não se valeram desta técnica, realizaram a coleta através de entrevistas e observações simples, em, no máximo 3 meses.

Com relação à análise de dados, houve predominância do emprego de análise de conteúdo e da análise por meio das fases do processo de translação, de Callon (1986). Nesse ponto, o conceito de simetria generalizada escapa e a consideração dos não-humanos nas análises fica muitas vezes restrita a indicar a interferência, o significado ou mesmo até desconsiderá-los. Poucas pesquisas valeram-se de técnicas mais abrangentes como análise de discurso (Teles, 2010), análise de narrativa (Lemos Júnior, 2017), análise temática (Camillis, 2016), binterlands com identificação de temas (Burtet, 2019) e cartografia das controvérsias (Bussular, 2017).

A partir das análises acima apresentadas e dos elementos que as nortearam, identificamos quatro caminhos adotados pelos pesquisadores brasileiros em trabalhos de tese de doutorado em Administração que indicam a TAR como base teórico e/ou metodológica, resumidos na Figura 1. 
Figura 1 - Espectro de emprego da TAR nas pesquisas nacionais.

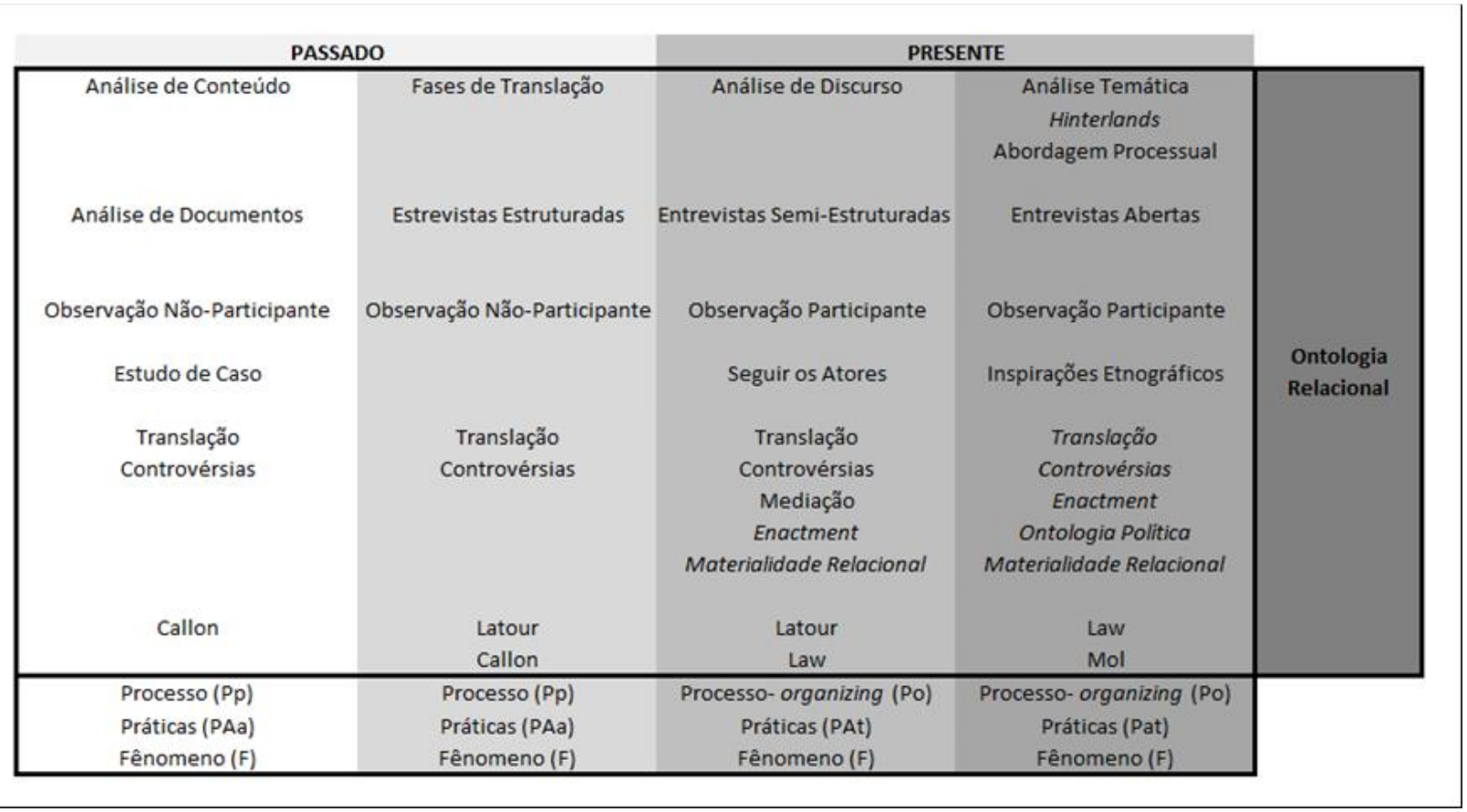

Fonte: elaborado pelos autores (2020)

As abordagens espalham-se em um continuum que mais as aproxima (ou afasta) da ontologia relacional proposta pela TAR e das discussões ligadas à noção de processo iniciadas pela TAR e Depois. Destacamos que as maneiras de abordar a unidade de análise (fenômeno, processo e prática), assim como a inclusão de outros conceitos teóricos, não se mostraram ser maior diferença nesse deslocamento pelo continuum, mas sim, as escolhas feitas com relação as estratégias de pesquisa, as técnicas de coletas de dados e as técnicas para análise dos dados utilizadas nas teses. A seguir, faremos a discussão de tais abordagens e dos desdobramentos destas escolhas para chegarmos aos caminhos possíveis para a adoção da TAR.

\section{Discussão dos Resultados: Reflexões sobre os percursos da TAR no Brasil}

A partir da leitura feita das teses selecionadas, alguns pontos chamam nossa atenção. Observa-se que poucas pesquisas fizeram a distinção das diferentes trajetórias percorridas pela TAR, apresentadas inicialmente neste artigo e tendo em Latour, Callon e Law seus autores principais. Cada trajetória tem características que as definem e as pesquisas pouco atentaram para tais delimitações. A maior parte dos trabalhos deu ênfase aos conceitos iniciais surgidos na década de 1980 e 1990, fazendo referências principalmente à Bruno Latour e Michel Callon. Poucos consideraram os desdobramentos apresentados pela Teoria Ator-Rede e Depois. Consequentemente, autores como John Law e outras mais recentes como Annemarie Mol e Vick Singleton, que se dedicaram a aprofundar o entendimento da ontologia relacional e da abordagem processual, são pouco explorados. Nota-se, inclusive, possíveis divergências epistemológicas ao empregar a TAR com caráter extremamente positivista, classificando fases de translação/tradução ou aplicando modelos teóricos analíticos prontos, afastando-se das origens e dos propósitos da TAR de explorar as relações. Por exemplo, pode-se dizer que é uma inconsistência, do ponto de vista epistemológico, usar a TAR em conjunto com análise de conteúdo da Bardin (2009).

Outro ponto de inconsistência observado, e que se afasta dos princípios relacionais da TAR, refere-se à estratégia de pesquisa. O método mais adotado foi o Estudo de Caso, o qual tem suas raízes em abordagens positivistas como as propostas por Yin (2001). O mesmo vale para usar o Estudo de Caso Interpretativista e/ou Construtivistas, visto que a TAR não busca interpretações da realidade e o próprio 
Latour (2003) criticou abertamente o construtivismo. Cabe destacar que existem outras possibilidades de emprego do Estudo de Caso que melhor se alinham com a TAR, como Stake (2005), que oferece uma releitura do Estudo de Caso voltada para estudos de caso instrumental, no qual um caso particular promove uma investigação mais ampla e onde não se busca generalização ou validade externa. Importante ressaltar que a TAR pode ser usada como método, por ser uma abordagem teórico-metodológica, seguindo os atores, sem a necessidade de ser amparada por outra estratégia de pesquisa, embora possamos utilizar as mais diversas técnicas de coleta de dados. O método de seguir os atores (humanos e nãohumanos) nos dá um grau de liberdade, ainda pouco explorado. De acordo com Latour (1999), a TAR é um método para entender o mundo em suas dinâmicas e relações políticas. Assim, o pressuposto metodológico de "seguir os atores" não deve ser confundido com a técnica de bola-de-neve, mas compreendido como: seguir, acompanhar, descrever e analisar as relações considerando humanos e nãohumanos, a partir do princípio de simetria e sem deixar de ser empiricamente realista (Lee \& Hassard, 1999).

Em relação ao tempo "em campo", podemos trazer o debate sobre as formas participativas de pesquisa e sua legitimidade na área de administração (Pozzebon, 2018). Uma das "impressões digitais" da TAR é a sua inspiração etnográfica, utilizando técnicas de coletas de dados e relatos de campo oriundos do método característico da Antropologia: observação participante, entrevistas semiestruturadas e em profundidade, uso de diário de campo, levando em consideração a presença e interação do pesquisador em campo, exigindo reflexividade. Poucas pesquisas se valeram de estratégias de pesquisas inspiradas na etnografia (ou a própria etnografia) que exigem um "trabalho de campo" mais extenso em termos de permanência em campo e profundidade dos relatos, e que não se detém na interpretação de realidades, mas busca a descrição e a performatividade da rede enquanto associações provisórias de elementos heterogêneos.

Nas pesquisas em Administração, sabe-se que a elaboração de uma etnografia requer um tempo considerável dada a densidade com que é realizada. As entrevistas não são feitas com questões fechadas, existe a empatia e a confiança que deve ser estabelecida entre o pesquisador e o informante (Cavedon, 1999) e tudo isso leva tempo, que dificilmente será inferior a 6 meses. Não estamos sendo ingênuos e desconsiderando o conflito entre o tempo necessário para a pesquisa e as exigências da produção acadêmica. Sabemos o quanto técnicas de inspiração etnográfica se refletem na dedicação ao trabalho de campo. Entretanto, se a pressão pela produção acadêmica impera, o emprego da TAR, em sua abordagem processual e ontologia relacional, tende a ficar restrita ou mesmo superficial.

Observa-se que muitas das pesquisas analisadas limitaram-se ao mapeamento dos principais atores humanos e não-humanos existentes num determinado contexto organizacional, sendo que a agência dos não-humanos ainda aparece de maneira tímida nos textos analisados, indicando uma lacuna que ainda deve ser preenchida. Além disso, a noção mais utilizada da TAR restringe-se ao processo de translação/tradução, independentemente do modo de utilizá-la (teoria/método/ambos), da estratégia de pesquisa adotada ou da duração da pesquisa. As pesquisas registraram o processo de translação a partir dos conceitos apresentados por Callon (1986), identificando as fases sequenciais de i) problematização, ii) interesse, iii) envolvimento e iv) mobilização, embora o próprio Callon (1986) destaque que a translação não pode ser reduzida a fases, pois representa momentos cuja realidade se sobrepõe em uma rede de associações. Isso indica uma fragilidade em nossas descrições a partir da TAR, refletida em pesquisas que se limitam a simplesmente descrever os processos.

Podemos dizer que as pesquisas nacionais focaram, na sua maioria, em conceitos elaborados na fase inicial da TAR, adotando-os, algumas vezes, de forma quase mecanicista. Observamos que noções de translação e de controvérsia foram tratadas, muitas vezes, como conceitos rígidos, e assim "aplicados" ou "encaixados" no campo da pesquisa. Entretanto, a revisão da literatura sobre a TAR aponta que a ideia de translação e controvérsia não operam como conceitos para serem simplesmente "aplicados". As investigações deveriam ser trabalhadas e elaboradas a partir dessas noções, com uma perspectiva mais 
fluída, ou seja, na descrição final do texto, que represente o "vai-e-vem" da realidade, que possibilite compreender as relações que se estabelecem no campo, trazendo as noções de translação e controvérsia para uma abordagem processual que entende o processo como recursivo.

Deste modo, conceitos como a translação e as controvérsias devem ser encarados como pressupostos que acompanham o pesquisador na coleta e análise dos dados. Em outras palavras, não focar nos conceitos em detrimento da sua descrição e compreensão. Controvérsias e translação praticamente tornam-se um objeto em si e não um meio para compreender o fenômeno, a prática ou o processo investigado. Além disso, o exercício de descrição na TAR passa por contar uma narrativa com relevância e propósito (storytelling) e não uma extensa linha do tempo com elementos relacionados a um fenômeno, processo ou prática organizacional. Qual a consequência disso? Excesso de descrições sem reflexividade do pesquisador e histórias neutras. Nossa provocação, e nosso próprio desafio, que compartilhamos aqui, é para que nossas pesquisas deem um passo a mais, buscando um maior nível de abstração e reflexão. A TAR exige descrição, entretanto, o problema não é a descrição em si, mas o que se faz com ela e o que ela diz sobre os actantes e suas relações.

Por fim, as pesquisas analisadas nos apontam a existência de dois caminhos que pavimentam o uso da TAR: um que se aproxima e outro que se afasta da ontologia relacional e da abordagem processual da TAR. Esses caminhos se distinguem entre "usar a TAR" - aplicando conceitos, identificando categorias de análise e mapeando redes e atores e "participar da agência da TAR" - apropriando-se de suas noções como um híbrido entre teoria, método, pesquisador e objeto de pesquisa (Figura 2). É neste último, que o pesquisador se permite inserir na rede heterogênea da pesquisa e descrever as relações visualizadas e, assim, performar a realidade.

Figura 2 - Os caminhos da TAR: aplicação ou apropriação

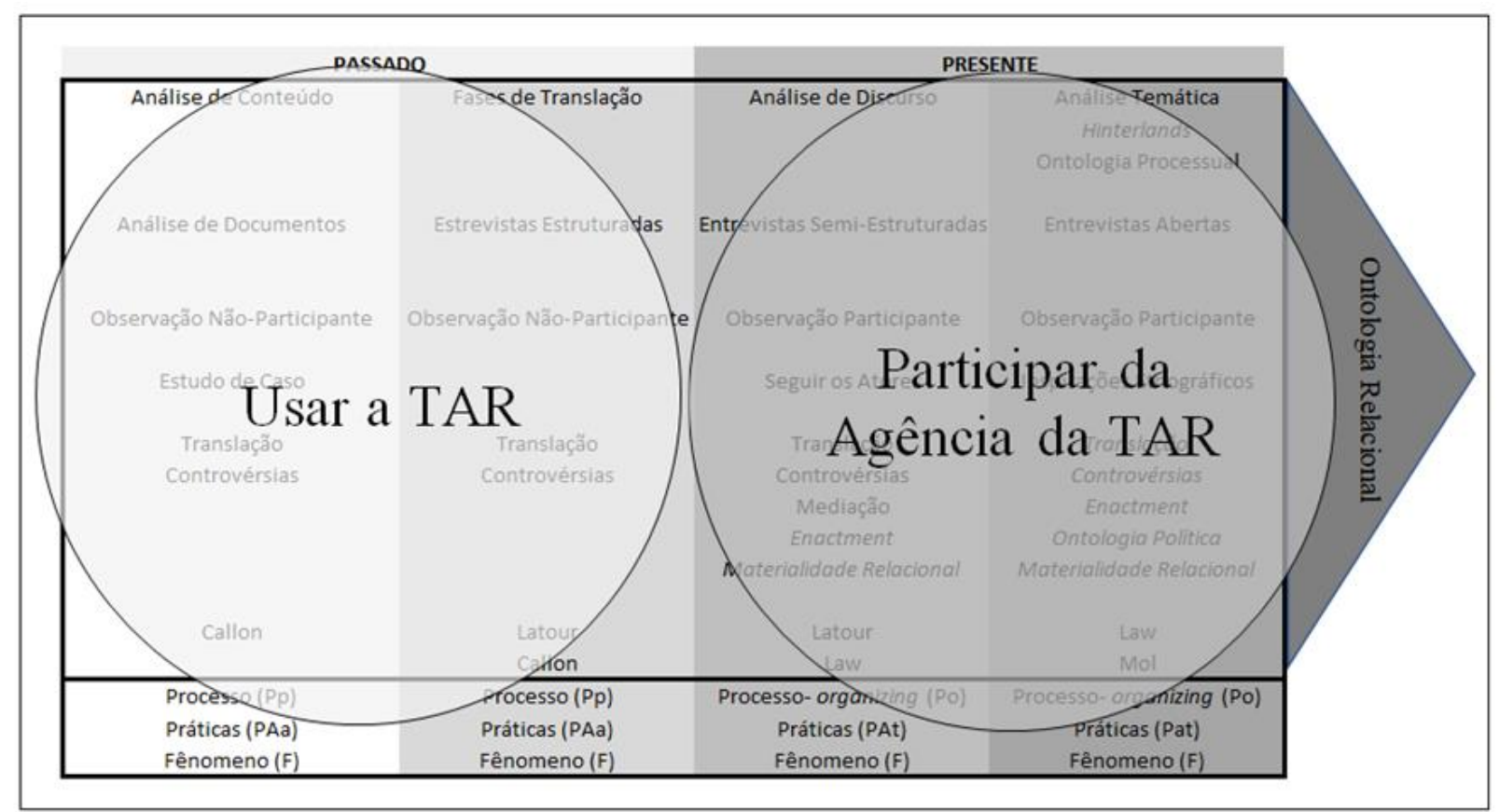

Fonte: elaborado pelos autores (2020).

A partir das análises feitas qualitativamente nos textos das teses, podemos dizer que a área de pesquisa em Administração no Brasil está cometendo excessos no "uso da TAR" enquanto ainda temos lacunas em "participar da agência da TAR". Ou seja, muita aplicação de conceitos e pouca exploração de aspectos relacionais e processuais que emergem do campo de pesquisa. Participar da agência da TAR, explorando seus aspectos teóricos e metodológicos ao mesmo tempo, possibilita abrir caminhos para aprofundar as noções e conceitos da TAR e Depois e da Pós-TAR, mas também para que possamos buscar o que pode 
ser uma Near ANT brasileira e como as pesquisas brasileiras em administração podem contribuir nas discussões sobre fractalidade, multiplicidade e performatividade. Mais do que isso, que outras noções nos são caras a partir da nossa realidade. Realidade essa da qual participamos e performamos. Podemos (e devemos) aproveitar essa liberdade que o movimento Near ANT apresenta para também transformá-la, aproveitando o seu caráter "móvel mutável" (Laet \& Mol, 2000).

Sendo assim, nós pesquisadores e pesquisadoras, em Administração no Brasil, precisamos ainda aprofundar a compreensão da TAR como projeto intelectual sem limites ou fronteiras determinadas, que só se mantem interessante e coerente com a realidade se for capaz de reinventar a si mesma (Blok et al., 2020). Para termos pesquisas "próximas à TAR" (Near ANT) parece-nos primeiramente necessário compreender a TAR como sendo um modo de fazer trabalho intelectual, performando práticas e sensibilidades intelectuais de não apenas conhecer, mas intervir no mundo e que desafiam a conceitualização estabelecida do que é o social. Se retomarmos as discussões sobre o que é o social para a TAR, retomamos as "associações de elementos heterogêneos" (Latour, 2012, p. 23). Ou ainda, como afirma Mol (2010, p. 265) "a TAR é uma rica matriz composta por maneira experimentais e explorativas de sintonizar com o mundo" o que nos impossibilita de olhar o campo (de pesquisa) estando do lado de fora e nos convida a participar da agência da TAR.

\section{Considerações e possibilidades de estudos futuros: Quais caminhos seguir?}

Uma das primeiras angústias que nos moveu na construção deste artigo diz respeito a dúvida de como elaborar uma pesquisa valendo-se da TAR, isto é, devemos empregá-la como lente teórica, como método, ou ambos. O que ficou claro para nós é que, nas pesquisas analisadas, qualquer uma destas escolhas é plausível. Porém, não chegamos, ao final, com um guia que permita definir critérios claros e inquestionáveis e que oriente definitivamente a escolha entre lente teórica, método ou ambos. Provavelmente porque propor um guia para TAR é uma simplificação precipitada e leviana dessa abordagem teórico-metodológica. Entretanto, o presente artigo contribui para a identificação de dois grandes caminhos distintos das pesquisas em Administração, no Brasil, que se valem da TAR, e serve como ponto de partida para uma reflexão crítica e posicionamento das pesquisadoras e pesquisadores da área, atuais e futuros.

Destacamos que a compreensão da TAR não é possível de ser feita sem uma leitura aprofundada de seus textos fundantes e preliminares (em sua maioria livros), inclusive anteriores a criação da expressão "Teoria Ator-rede" e seus autores influenciadores. Além disso, é preciso compreender o aspecto mutável da TAR e seus desdobramentos em TAR e Depois até as discussões e possibilidades mais recentes. Isso nos parece imprescindível para que possamos nos posicionar nesta possível Near ANT e buscar coerência em nossas escolhas teórico-metodológicas. Ao final do nosso percurso, escolhemos duas questões que ainda nos inquietam, a fim de deixarmos como provocação a nós e aos nossos pares, abrindo possibilidades para estudos futuros que possam aprofundar o debate.

A primeira questão é compreender e considerar os desdobramentos que fizeram surgir a TAR e Depois e que segue se desdobrando. A provocação aqui é trazer questionamentos sobre o que a TAR nos possibilita performar que outras teorias e/ou métodos não possibilitam? Essa resposta precisa estar clara quando se decide trabalhar com a TAR, para que não tenhamos, ao final da pesquisa, só mais uma "teoria da moda" usada e aplicada em uma tese, mas sim que possamos "participar da agência da TAR". Para evitar esse percalço é importante explorar a ontologia política e o aspecto crítico da TAR, em especial com os conceitos advindos a partir da TAR e Depois. Para ilustrar, podemos trazer o conceito da metafísica da presença, no qual nem tudo pode ser levado à presença, ou que, tornar as coisas presentes é necessariamente torná-las ausentes, simultaneamente. Nessa perspectiva, não podemos compreender os objetos a menos que também pensemos neles como um conjunto presente de dinâmicas geradas e geradoras de realidades que estão necessariamente ausentes (Law \& Singleton, 2005). Pode-se, desta maneira, rever muitos dos trabalhos realizados e refletir sobre quais os processos, os pressupostos e os 
actantes identificados (ou não identificados) que poderiam (ou até deveriam) estar presentes, mas não estavam.

Em algumas pesquisas analisadas os conceitos se aproximam de uma ontologia relacional e da abordagem processual da TAR, mas em outras (a maioria ainda) se afastam. A questão aqui não se trata de certo ou errado, mas de que as escolhas precisam ser coerentes e conscientes das limitações e possibilidades que cada aproximação traz. Isso nos obrigará a retornar às discussões ontológicas e epistemológicas da TAR, e, consequentemente, metodológicas, para buscar coerência no desenvolvimento da pesquisa. Talvez uma provocação extra que possa ser feita aqui é: seria a TAR tão flexível a ponto de "aceitar" abordagens ontológicas e epistemológicas opostas?

A segunda questão é uma sugestão para os pesquisadores que já realizaram suas pesquisas com a TAR responderem a seguinte pergunta: Qual é o método da TAR? Embora algumas teses indiquem que tenha sido usada a TAR como teoria e como método, a maioria se ampara em outros métodos de pesquisa para justificar e descrever procedimentos metodológicos. Acreditamos que uma discussão aprofundada sobre procedimentos metodológicos de pesquisa a partir da TAR merece ser feita. Uma vez que a possibilidade de realizarmos pesquisas "Near ANT" (que sejam próximas a TAR) nos traz uma liberdade que parece não ter fim, teríamos um limite ou não para o que pode se aproximar da TAR?

Desta forma, para estudos futuros, sugerimos dois recortes a serem explorados que contribuirão para que se qualifique ainda mais as pesquisas em Administração no Brasil. O primeiro está relacionado a compreensão do método da TAR e suas combinações: (1) aprofundar a análise sobre os métodos de pesquisa que foram e têm sido utilizados em combinação com a TAR e discutir o que seria o método TAR, (2) analisar a correlação entre objeto de estudo e método aplicado, explorando as particularidades das áreas da Administração nas quais as pesquisas estão inseridas, como os métodos tradicionalmente utilizados e suas diferenças com relação à TAR.

O segundo recorte para estudos futuros, também resultado desta investigação, dado que alguns conceitos da TAR são mais amplamente utilizados nas pesquisas, é analisar em profundidade estes principais conceitos, em especial controvérsias e translação - apontando a diferença entre tratar esses conceitos a partir da análise de conteúdo e análise temática, por exemplo, ou ainda quais as definições de controvérsia surgem quando os estudos participam da agência da TAR - propondo, assim, novas trajetórias possíveis.

Com relação as limitações desta pesquisa, destacamos que nossa análise ficou restrita ao texto publicado das teses o que, embora tenha sido uma escolha, foi também uma limitação. Não foram analisadas as redes de pesquisadores e programas de pós-graduação que participaram da construção de cada tese. Não verificamos a trajetória acadêmica de cada pesquisador, buscando, por exemplo, se na dissertação foi seguida a mesma linha teórica-metodológica da tese. Não foram feitas entrevistas com os pesquisadores para compreender o processo de inclusão ou exclusão de elementos, noções e conceitos de cada texto. Ou seja, não exploramos a rede. A partir disso, as análises podem ser ampliadas e aprofundadas. Desta forma, uma sugestão adicional de estudos futuros é "seguir os atores" que construíram e constroem a rede, neste caso, as teses.

Por fim, mesmo limitados aos textos de tese, foi possível observar o intricado e amplo arcabouço teóricometodológico existente nas pesquisas na área de Administração no Brasil. Verifica-se, todavia, que a TAR pode ser muito mais do que uma simples ferramenta empregada para identificar e descrever os diferentes atores num contexto organizacional. A apropriação da TAR pode permitir fazer indagações e análises a partir de sua ontologia relacional, contemplando aspectos mutáveis no tempo e no espaço, e suas consequentes implicações. Entretanto, essa apropriação precisa ser feita de maneira que o pesquisador se permita participar da agência com a TAR. Por fim, temos o desafio de, ao trabalhar com a TAR, não limitar nossos textos a apresentações que condizem com modelo do mainstream acadêmico: em especial na separação clássica entre teoria e método, já que a TAR se coloca como uma abordagem teóricametodológica, e muitos de nós assumimos isso nos textos (ou repetimos a citação). É claro que não 
podemos deixar de registrar que temos uma "exigência" do campo científico que ainda apresenta heranças bastante positivistas que separam cada etapa da pesquisa. Entretanto, fica a provocação: participar da agência da TAR é compreender que performamos a realidade ao realizar nossas pesquisas.

\section{Referências}

Adachi, T. (2011). Comitê Gestor da Internet no Brasil (CGI.BR): uma evolução do Sistema de Informação Nacional moldada socialmente. Tese de doutorado. USP, São Paulo.

Alcadipani, R., \& Hassard, J. (2010). Actor-Network Theory, organizations and critique: Towards a politics of organizing. Organization, 17(4), 419-435. https://doi.org/10.1177/1350508410364441

Alcadipani, R., \& Tureta, C. (2009). Teoria ator-rede e estudos críticos em administração : possibilidades de um diálogo. Cadernos EBAPE.BR, 7(3), 406-418.

Alverga, P. R. de. (2017). Controvérsias na implementação de um sistema de informação sob a perspectiva da Teoria Ator-Rede: estudo de caso em uma organização do poder judiciário. Tese de doutorado. Universidade Federal do Rio Grande do Norte, Natal.

Amantino-de-Andrade, J. (2004). Actor-network theory (ANT): uma tradução para compreender o relacional e o estrutural nas redes interorganizacionais? Cadernos EBAPE.BR, 2(2), 1-14.

Américo, B. L., \& Takahashi, A. R. W. (2013). Estudos organizacionais de aprendizagem e conhecimento à luz das abordagens situada e da tecnociência. Cadernos EBAPE.BR, 11(4), 588-607.

Andrade, A. D. S. C. G. DE. (2013). Trajetórias de Implantação do Projudi à Luz da Teoria Ator-Rede (Vol. 1). Tese de doutorado. FGV, Rio de Janeiro.

Arimatéia, J. De, Valadão, D., \& Andrade, J. A. De. (2019). Análise de Tecnologias Sociais sob a Luz da Teoria do Ator-Rede. Desenvolvimento Em Questão, 17(48), 231-249.

Bardin, L. (2009). Análise de Conteúdo. Lisboa Edições.

Blok, A., Farías, I., \& Roberts, C. (2020). The Routledge Companion to Actor-Network Theory. London: Routledge.

Burtet, C. G. (2019). (Re)pensando a inovação e o conceito de inovação inclusiva: um estudo do movimento maker no Brasil à luz da Teoria Ator-Rede. Tese de doutorado. UNISINOS, Porto Alegre.

Bussular, C. Z. (2017). A amargura do rio que era doce: às margens da lama e dos processos de aprender a organizar. Tese de doutorado. Universidade Federal do Rio Grande do Sul, Porto Alegre.

Callon, M. (1986). Some Elements of a Sociology of Translation-Domestication of the Scallops and the Fishermen of St-Brieuc Bay. Power, Action and Belief: A New Sociology of Knowledge?, 196-223.

Camillis, P. K. De. (2016). Organizando com barro: a bioconstrução como prática de cooperação. Tese de doutorado. Universidade Federal do Rio Grande do Sul, Porto Alegre.

Camillis, P. K. de, \& Antonello, C. S. (2016). Da translação para o enactar : contribuições da Teoria Ator-Rede para a abordagem processual das organizações. Cadernos EBAPE.BR, 14(1), 61-82.

Cavalcanti, M. F. R., \& Alcadipani, R. (2013). Organizações como processos e Teoria Ator- Rede : A contribuição de John Law para os Estudos Organizacionais. Cadernos EBAPE.BR, 11(4), 556-568.

Cavedon, N. R. (1999). O método etnográfico em estudos sobre a cultura organizacional; implicações positivas e negativas. Encontro Nacional Dos Programas de Pós-Graduação Em Administração, 23, 1-15.

Cerretto, C., \& Domenico, S. M. R. De. (2016). Mudança e Teoria Ator-Rede : Humanos e Não Humanos em Controvérsias na Implementação de um Centro de Serviços Compartilhados. Tese de 
doutorado. FGV - EBAPE, 14(1), 83-115.

Cooper, Robert;, \& Burrell, G. (1988). Modernism, postmodernism and organizational analysis 2: the contribution of Michel Foucault. Organization Studies, 9(2), 221-235.

Cooper, Robert. (1976). The Open Field. Humans Relations, 29(11), 999-1017.

Cooper, Robert, \& Law, J. (2015). Distal and proximal views. In For Robert Cooper (pp. 207-243).

Routledge.

Duarte, M. de F. (2015). Práticas de organizar na indústria criativa: a produção de um espetáculo de teatro musical em São Paulão-SP. Tese de doutorado. FGV, São Paulo.

Duarte, M. de F., \& Alcadipani, R. (2016). Contribuições do organizar (organizing) para os Estudos Organizacionais. Organizações \& Sociedade, 23(76), 57-72. https://doi.org/10.1590/1984-9230763

Duque, O., \& Valadão, D. A. D. (2017). Abordagens teóricas de tecnologia social no Brasil. Pensamento Contemporâneo Em Administraçaõ, 11(5), 1-19.

Fornazin, M. (2015). A informatização da saúde no Brasil: uma análise Multi-Paper inspirada na Teoria AtorRede. Tese de doutorado. FGV, Rio de Janeiro.

Gad, C., \& Jensen, C. B. (2010). On the Consequences of Post-ANT. Science, Technology \& Human Values, 35(1), 55-80. https://doi.org/10.4337/9781788113861.00012

Giddens, A. (1984). The constitution of society: Outline of the theory of structuration. University of California Press.

Lacruz, A. J., Américo, B. L., \& Carniel, F. (2017). Teoria ator-rede em estudos organizacionais : análise da produção científica no Brasil. Cadernos EBAPE.BR, 15(3), 574-598.

Laet, M. de, \& Mol, A. (2000). The Zimbabwe Bush Pump: Meachanics of a Fluid Technology. Social Studies of Science, 30(2), 225-263.

Latour, B. (1994). Jamais Fomos Modernos: Ensaio de Antropologia Simétrica. Rio de Janeiro: Editora 34.

Latour, B. (1999). On Recalling ANT. The Sociological Review, 47(1_suppl), 15-25.

https://doi.org/10.1111/j.1467-954X.1999.tb03480.x

Latour, B. (2000). Ciência em ação: como seguir cientistas e engenheiros sociedade afora. In Unesp. https://doi.org/10.1590/S1414-32832000000100014

Latour, B. (2001). A Esperança de Pandora: ensaios sobre a realidade dos estudos cientificos. Bauru, SP: EDUSC.

Latour, B. (2003). The promises of constructivism *. In D. Ihde (Ed.), Chasing Technology : Matrix of Materiality, Indiana Series for the Philosophy of Science (pp. 27-46). Bloomington, IN: Indiana University Press.

Latour, B. (2004). Políticas da Natureza: como fazer ciência na democracia. Bauru, SP: EDUSC.

Latour, B. (2005). Reassembling the Social. An Introduction to Actor-Network-Theory.

https://doi.org/10.17323/1726-3247-2013-2-73-87

Latour, B. (2012). Reagregando o Social: uma introdução à teoria do ator-rede. Salvador, BA: EDUFBAEDUSC.

Latour, B., \& Woolgar, S. (1997). A Vida de Laboratório: a produção de fatos científicos. Rio de Janeiro: Relume Dumará.

Law, J. (1992). Notes on the theory of the actor-network: Ordering, strategy, and heterogeneity. Systems Practice, 5(4), 379-393. https://doi.org/10.1007/BF01059830

Law, J. (1994). Organizing Modernity. Oxford: Blackwell. 
Law, J. (1999). Traduction / Trahison: Notes on ANT. Centre for Science Studies, Lancaster University, p. $1-15$.

Law, J. (2002). Objects and Spaces. Theory, Culture \& Society, 19(5-6), 91-105.

Law, J. (2004). After Method: Mess in Social Science Research. New York: Routledge.

Law, J., \& Hassard, J. (1999). After ANT: Complexity, Naming and Topology.

https://doi.org/10.1111/j.1467-954x.1999.tb03479.x

Law, J., \& Lodge, P. (1984). Science for Social Scientists. Springer.

Law, J., \& Mol, A. (1995). Notes on materiality and sociality. The Sociological Review, 43(2), 274-294.

https://doi.org/10.1111/j.1467-954X.1995.tb00604.x

Law, J., \& Singleton, V. (2005). Object Lessons. Organization, 12(3), 331-355.

https://doi.org/10.1080/02560046.2018.1437195

Law, J., \& Urry, J. (2004). Enacting the social. Economy and Society, 33(3), 390-410.

https://doi.org/10.1080/0308514042000225716

Lee, N., \& Hassard, J. (1999). Organization Unbound: Actor-Network Theory, Research Strategy and Institutional Flexibility. Organization, 6(3), 391-404.

Lemos Júnior, L. C. (2017). Modelo de negócio: uma lente pós-estruturalista para configuração de valor. Tese de doutorado. Universidade Presbiteriana Mackenzie, São Paulo.

Luz, L. H. da. (2016). Estratégia emergente na lógica da multidão: uma abordagem a partir de iniciativas da multidão, do comum e da Teoria Ator-Rede. Tese de doutorado. UNISINOS, São Leopoldo.

Mackenzie, D., Muniesa, F., \& Siu, L. (2007). Do Economists Make Markets?: on the performativity of economics. https://doi.org/10.4000/sdt.16906

Mol, A. (2002). The Body Multiple: Ontology in Medical Practice. https://doi.org/10.1215/9780822384151

Mol, A. (2010). Actor-Network Theory: sensitive terms and enduring tensions. Kölner Zeitschrift Für Soziologie Und Sozialpsychologie, 50(1), 253-269.

Mol, A., \& Law, J. (1994). Regions, Networks and Fluids: Anaemia and Social Topology. Social Studies of Science, 24(4), 641-671.

Okoli, C. (2015). The View form Giant's Shoulders: Devoloping Theory with Theory-Mining Sistematic Literature Reviews. 1-78.

Oliveira, V. M. de, \& Valadão, J. de A. D. (2017). Entre a simplificação e a complexidade, a heterogeneidade : Teoria Ator-Rede e uma nova epistemologia para os estudos organizacionais. Cadernos EBAPE.BR, 15(4), 877-899.

Pereira, M. C. G. (2016). Água e convivência com o semiárido: múltiplas águas, distribuições e realidades. Tese de doutorado. FGV, São Paulo.

Pinto, C. C. (2013). Mudança e a Teoria Ator-Rede: Humanos e não-bumanos em controvérsias na implementação de um Centro de Serviços Compartilhados . Tese de doutorado. Universidade Presbiteriana Mackenzie. https://doi.org/10.1016/j.jns.2003.09.014

Pozzebon, M. (2018). From aseptic distance to passionate engagement: reflections about the place and value of participatory inquiry. RAUSP Management Journal, 53(2), 280-284.

Reed, M. (1997). In Praise of Duality and Dualism: Rethinking Agency and Structure in Organizational Analysis. Organization Studies, 18(1), 21-42. https://doi.org/10.1177/017084069701800103

Rowe, F. (2014). What literature review is not: Diversity, boundaries and recommendations. European Journal of Information Systems, 23(3), 241-255. https://doi.org/10.1057/ejis.2014.7 
Santos, H. (2011). Trabalho Móvel: em trânsito por aeroportos e aviões. Tese de doutorado. FGV, São Paulo.

Santos, L. L. da S., \& Alcadipani, R. (2015). Por uma Epistemologia das Práticas Organizacionais: A contribuição de Theodore Schatzki. Organizações \& Sociedade, 22(72), 79-98. Retrieved from http://www.redalyc.org/html/4006/400638362005/

Schwarz, A., Johnson, N., \& Chin, W. W. (2007). Understanding Frameworks and Reviews : A Commentary to Assist us in Moving Our Field Forward by Analyzing Our Past 1. Review Literature And Arts Of The Americas, 38(3), 29-50. https://doi.org/http://doi.acm.org/10.1145/1278253.1278259

Soares, C. D. M. (2016). Inclusão Digital E Participação Eletrônica: Uma Investigação Multi-Paper. Tese de doutorado. FGV, Rio de Janeiro.

Stake, R. E. (2005). Qualitive Case Studie. In The Sage handbook of qualitative research (3rd ed., pp. $443-$ 466). London: SAGE Publications.

Teles, A. (2010). Piraí digital e a Teoria Ator-Rede: a trajetória de inclusão e desenvolvimento de Piraí. Tese de doutorado. FGV, Rio de Janeiro.

Tonelli, D. F. (2015). Origens e afiliações epistemológicas da Teoria Ator-Rede : implicações para a análise organizacional. Cadernos EBAPE.BR, 14(2), 377-390.

Tureta, C. (2011). Práticas organizativas em escolas de samba: o setor de harmonia na produção do desfile do VaiVai. Tese de doutorado. FGV, São Paulo.

Tureta, C, \& Alcadipani, R. (2009). O objeto objeto na análise organizacional : a teoria ator-rede como método de análise da participação dos não-humanos no processo organizativo. Cadernos EBAPE.BR, 7(1), 51-70.

Valadão, José de Arimatéia Dias, Neto, J. R. C., \& Andrade, J. A. de. (2017). Bases sociotécnicas de uma Tecnologia Social: o transladar da Pedagogia da Alternância em Rondônia. Organizaç̧ão \& Sociedade, 24(80), 89-114. https://doi.org/10.1590/1984-9230805

Valadão, José de Arimatéias Dias. (2014). Seguindo Associações Sociotécnicas sob a luz da Teoria do Ator-Rede: uma tradução da pedagocia da alternância para rotinas e tecnologias sociais. Tese de doutorado. Universidade Federal de Pernambuco, Recife.

Walsham, G. (1997). Actor-network theory and IS research: current status and future prospects. In LEE, A.; LIEBENAU, J.; DEGROSS, J. (Orgs.). Information systems and qualitative research. (pp. 467-480). London: Chapman and Hall.

Weick, K. E. (1979). The Social Psychology of Organizing (2 Ed.). MA: Addison-Wesley.

Whittle, A., Spicer, A., \& Whittle, A. (2008). Organization Studies Essai Is Actor Network Theory Critique ? Organization Studies, 29(4), 611-629. https://doi.org/10.1177/0170840607082223

Yin, R. K. (2001). Estudo de caso: planejamento e métodos (2 Ed.). Porto Alegre: Bookman. 